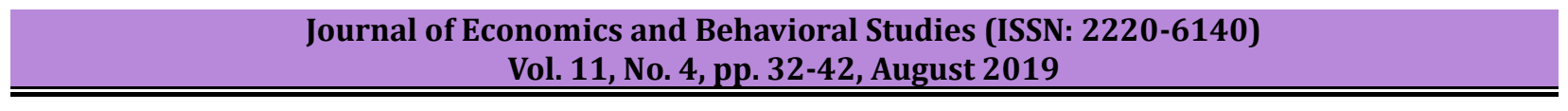

\title{
Feeding Management and Extent of Commercialisation among the Smallholder Dairy Farmers in Zimbabwe
}

\author{
Tawedzegwa Musitini, Abbysinia Mushunje, Joseph Muroiwa \\ Department of Agricultural Economics and Extension, University of Fort Hare, South Africa \\ towersmusitini@yahoo.co.uk,AMushunje@ufh.ac.za, josemuroiwa@gmail.com
}

\begin{abstract}
This study assessed the effects of grazing and feeding management on the extent of commercialization among the smallholder dairy farmers in Zimbabwe. Using a sample of 225 smallholder dairy farming households selected randomly across 11 smallholder dairy cooperatives in Zimbabwe, data were analysed using descriptive statistics and the ordinary least squares regression method. The study used milk yield as a proxy for commercialization. Farmers whose cows produced higher yield were considered more commercialized than farmers whose cows produced a lower yield. The results indicated that access to better pastures, better feed types, more area under fodder and more feeding frequency positively impact on milk yield. This result indicates that smallholder farmers with better access to enough, appropriate and consistent feed obtain better milk yield from the dairy cows while the poor quality and quantity of feeds are the primary reasons why most smallholder dairy farmers in developing countries like Zimbabwe continue to produce low/uneconomic milk yields. Since purchased dairy feed concentrates are essential in enhancing milk yield, the study recommends that farmers who can afford these should continue using them and where applicable agro-dealers selling these inputs should be supported to establish selling outlets within the farmers reach. However, given the cost of the commercial dairy feeds visa the economic capacity of smallholder milk producers, the study recommends farmer to consider producing their feed by putting more area under fodder than buying commercial feed.
\end{abstract}

\section{Keywords: Fodder, pasture, Ordinary Least Squares regression, smallholder farmer, grazing.}

\section{Introduction}

Livestock including dairy cows performs multiple functions within the smallholder farming systems. They provide milk which is a crucial and affordable food source, manure which acts as input required for crop and vegetable production through enhancing soil productivity and fertility, cash income provision as well as in enhancing savings, investments and employment (Ngongoni et al., 2007; Afzal, 2010; Aweke, 2017). Unlike other agricultural enterprises like crop production which are often seasonal, milk provides farming households with regular income throughout the year (Moran, 2009; Pandey \& Voskuil, 2011). Moreover, dairy farming provides alternative employment opportunities for the rural farm and non-farm economy. A study on enhancing and re-designing smallholder dairy farming in Pakistan conducted by Afzal (2009) found that for each 20 litres of raw milk produced within the smallholder farming sector per day, one full-time wage employment is created. Similarly, a study conducted by Rodriguez (1987) in Zimbabwe found milk to be a source of livelihoods and employment not only for the producing farming households but also for many value chain actors along the milk cold chain. With these several functions, enhancing the productivity and commercialisation of smallholder.

Dairy farming can serve as a vehicle for improving smallholder farmers' livelihoods, providing income and food security. Research shows that milk yields in the smallholder dairy sector in many developing countries are usually low, ranging from as low as 2 to 5 litres per cow per day (Marius et al., 2011). One of the most significant critical challenges affecting the smallholder dairy farming sector in the developing countries is both the quality and quantity of the feeding used (Moran, 2009; Afzal, 2010; FAO, 2010; Pandey \& Voskuil, 2011; Kipkirui \& Otieno, 2017). While milk productivity and the delivery by large scale commercial dairy farmers is usually constant all year round, the quantity of milk produced within the smallholder dairy farming sector in developing countries significantly decreases by up to $35 \%$ during the dry season because of limited access to appropriate feeds (Pandey \& Voskuil, 2011). This shows that the poor quality and quantity of feeds are the main reason why smallholder milk producers in developing countries continue to produce low milk yields (Kipkirui \& Otieno, 2017). Majority of the smallholder milk producers in Africa lack the knowledge and experience of efficient and appropriate utilisation of animal feed resources (NABC, 2014). In addition, a review of related literature on smallholder milk productivity in Zimbabwe revealed a few gaps. 
Most of the studies on small scale dairy farming conducted in Zimbabwe (e.g. Mupunga \& Dube, 1993; Hanyani-Mlambo et al., 1998; Gran et al., 2002; Ngongoni et al., 2006; Marius et al., 2011; SNV, 2012; Shangurai, 2013) have researched on the general issues affecting the sector without explicitly addressing the grazing, feeding and nutrition issues in detail. A review of literature on this subject further reveals that the majority of studies which adequately addressed effects of feeding and nutrition on milk productivity among the smallholder dairy farmers have been conducted outside Zimbabwe (Omiti et al., 2009; Land O'Lakes, 2010; Gachuiri et al., 2012; Kipkirui \& Otieno, 2017; Meja et al., 2017; Aweke, 2017). These studies were done in East Africa mainly in Kenya and Ethiopia. It is for these reasons that this study seeks to explore the relationships between grazing, feeding management, nutrition and commercialisation of smallholder dairy farmers in Zimbabwe using descriptive statistics and the Ordinary Least Squares (OLS) regression model. Milk yield was chosen as the determinant of productivity because it is the most universally accepted measure of this component. This study examines the milk yield levels of cows getting different feed types and different feeding intervals. As such, the remainder of this study is structured into three sections. The next phase presents the research methodology, where the conceptual framework and the econometric models are outlined.

\section{Literature Review}

An Overview of Smallholder Dairy Farming in Developing Countries: This section presents a brief overview of smallholder dairy farming in general followed by a discussion of smallholder dairy farming in Zimbabwe. Research shows that smallholder farmers in developing countries have a long history of producing milk. Apart from producing milk for household consumption, hence improving the nutritional status of the rural population, the dairy enterprises provide income as well as employment to many people (FAO, 2010; USAID, 2018). However, most milk in developing countries is still produced in traditional smallscale systems with little or no mechanisation or technological advancement and innovations (Gerosa \& Skoet, 2012). While the milk and the dairy sector in most developed countries have shifted towards larger herds and greater milk productivity per cow, the situation in Africa has remained poor. Larger herd sizes allow for the adoption of technologies and systems that require more substantial capital investments (Muehlhoff et al., 2013). As a result, despite the growing demand in milk and other dairy products, a study by Kandjou (2011) revealed that small-scale milk producers in the developing countries of Africa face several problems in realising the opportunities offered by growing demand for dairy products.

An Overview of Dairy Farming in Zimbabwe: The dairy sector in Zimbabwe is made of predominantly two groups; the large-scale commercial and smallscale sectors. The most significant difference between these categories is the scale of production (Rodriguez 1987; Mpofu 2007; Mugweni and Muponda 2015). The largescale sector has large farms with high producing $(>5000 \mathrm{~kg} /$ lactation) pure exotic dairy breeds and their crosses and accounts for more than $98 \%$ of formally marketed milk while the smallholder sector contributes only $1-2 \%$ of the formally marketed national milk production (Ngongoni et al., 2006). The large-scale sector consists predominantly of white farmers, with herd sizes of up to 90 purebred animals working in commercially conducive environments while the smallholder sector consists of the indigenous black people operating under predominantly subsistence conditions (Hanyani-Mlambo, 2000). Unlike the large-scale commercial dairy sector which has substantial commercial linkages with the dairy processing firms, the smallholder dairy sector is mainly characterised by weak institutional linkages to dairy processors (Mugweni \& Muponda, 2015).

Smallholder Dairy Production Constraints in Zimbabwe: Unlike the large scale commercial dairy farmers who run viable and profitable dairy enterprises, the smallholder dairy farmers in Zimbabwe face several limitations. However, the bulk of the milk produced in the small-scale dairy sector is mainly for local consumption within the producing localities with the surplus sold through the Milk Collection Centres (Mugweni \& Muponda, 2015). First, the smallholder dairy sector in Zimbabwe is characterised by a firm reliance on family labour, a weak resource base, use of primitive technologies, poorly developed infrastructures, weak institutional connections, and uneconomic production levels and very few smallholder farmers have access to cash to hire extra labour (Hanyani-Mlambo, 2000). Moreover, small-scale dairy farmers in Zimbabwe predominantly use local indigenous breeds for dairy which though well adapted to the marginal production conditions, have poor dairy characteristics (Mpofu, 2007). 
Furthermore, smallholder dairy farmers in Zimbabwe own 1-3 cows, which are overall too low to justify commercial viability (Ngongoni et al., 2007). Key among the factors hindering milk production within the smallholder dairy sector in Zimbabwe are shortages of feeds, limited access to liquid cash and poor farm records (Hanyani-Mlambo, 2000). The large-scale commercial dairy farmers use some organised cooperative transport system to send their milk directly to the processors (Matekenya, 2016). According to Topps \& Oliver (1993), the poor levels of feeding and nutrition management are among the fundamental causes of the uneconomic yields, poor calving rates, late calving and prolonged calving intervals among the small scale milk producers in Zimbabwe. A study by Ngongoni et al. (2007) on the factors influencing dairy milk production in the smallscale dairy sector of Zimbabwe revealed that inadequate nutrition caused acute reproductive challenges such as retained placenta and long post partum anoestrus periods. In the absence of supplemented protein concentrate, the dairy cattle grazing natural pasture have high chances of losing body weight with cyclic ovarian activity ceasing when cows lost $20-30 \%$ of their mature weight due to undernutrition (Topps \& Oliver, 1993). Further, a study by Marius et al. (2011) showed that the dairy farming households that supplemented their feeding produced significantly more milk than those that did not supplement.

The same study revealed that during the rainy season, the dairy animals even for the smallholder sector gained weight and milk production was high, while during the dry season the yield and body condition of the cows significantly declined (Marius et al., 2011). Majority of smallholder dairy farmers in Zimbabwe rely on natural pastures for feeding the dairy animals. A study by Ngongoni et al. (2007) on the factors affecting milk production in the smallholder dairy sector of Zimbabwe show that natural pasture accounts for $90 \%$ of the feed that given to the dairy cows during the wet season. The same study by Ngongoni et al. (2007) also shows that other feeds such as maize stover and fodder mainly Napier and Bana grass contributes the remaining $10 \%$ of the overall feed available in the smallholder dairy sector. Sadly, the natural grazing systems provide limited capacity for intensification of dairy production. Research shows that under-nutrition because of low energy consumption negatively affects oestrus cycles, ovulation and fertilisation in dairy cows (Topps \& Oliver, 1993). An evaluation of small-scale dairy farming in Zimbabwe conducted by the SNV Netherlands Development Services in 2012 revealed that the use of own silage among the smallholder milk producers was still deficient most likely because of reliance on grazing. The same study by the SNV also revealed a high usage of natural communal grazing across all projects with the average area allocated to fodder production averaging $0.9 \mathrm{ha} /$ farmer $(\mathrm{SNV}, 2012)$.

\section{Methodology}

Data: The study applied cross-sectional research design. Before data collection, a comprehensive list of 21 active small-scale dairy cooperatives with a combined active membership of 517 smallholder farmers was obtained from the Zimbabwe Association of Dairy Farmers (ZADF). The Yamane's formula for calculating sample size was used to determine the sample size. A renowned mathematical statistician Taro Yamane developed this formula in 1967, and different researchers across disciplines have used it over the years (Israel, 2003). The rationale for adequate calculation of the sample size was to enable the researcher to generalize the conclusions reached after analysing the data to the entire population under study. Below is the mathematical equation for the Yamane's formula that was used to decide the sample size at a $95 \%$ confidence interval.

$$
n=\frac{N}{1+N\left(e^{2}\right)}
$$

Where $\mathrm{n}$ is the sample size, $\mathrm{N}$ is the population size, and e is the level of precision. When this formula was applied to this study, a sample of 221 farmers was determined as the minimum target for this study. The data was gathered from 225 small scale milk producers (176 male, 49 female) randomly selected from 11 small scale dairy cooperatives in Zimbabwe. A three-level multistage sampling method was applied. First, 11 smallholder dairy cooperatives were selected using simple random sampling. The simple random sampling method gives every element of the population (in this case a smallholder dairy cooperative) an equal chance of being included in the sample. With this method, each component of the population is selected independent of one another, and without replacement thus no item can be selected twice (Personal, Archive, Kundurjiev, \& Salchev, 2011). Second, the probability proportional to size was applied to determine the number of units to be reached in each cluster. 


\section{Journal of Economics and Behavioral Studies (ISSN: 2220-6140)}

Vol. 11, No. 4, pp. 32-42, August 2019

Finally, simple random sampling was again used to select the survey respondents in each cluster. Figure 1 below shows the map of Zimbabwe indicating study area while Table 1 summarizes the final sample for the locations and number of farmers interviewed in each area.

Table 1: Summary of Farmers Reached for the Survey per Each Location

\begin{tabular}{|c|c|c|c|c|c|c|}
\hline \multirow[b]{2}{*}{ Province } & \multirow[t]{2}{*}{ Dairy Project } & \multirow[t]{2}{*}{ District } & \multirow[b]{2}{*}{ Location } & \multicolumn{2}{|c|}{ Respondents } & \multirow[b]{2}{*}{ Total } \\
\hline & & & & Female & Male & \\
\hline & Chikwaka & Goromonzi & Juru GP & 5 & 12 & 17 \\
\hline & Domboshava & Goromonzi & Damboshawa & 4 & 13 & 17 \\
\hline & Chitomborwizi & Chinhoyi & Crawford Farm & - & 13 & 13 \\
\hline & Marirangwe & Beatrice & Marirangwe BC & 5 & 33 & 38 \\
\hline \multirow[t]{2}{*}{ Mash East } & Murehwa & Murewa & Murewa 44 BC & 8 & 4 & 12 \\
\hline & Rusitu Dairy & Chipinge & Rusitu Valley & 8 & 34 & 42 \\
\hline Manicaland & Upperand & Chipinge & Rusitu Valley & 3 & 12 & 15 \\
\hline Masvingo & Hamaruomba & Masvingo & Mushagashe BC & 7 & 20 & 27 \\
\hline \multirow[t]{2}{*}{ Midlands } & Gokwe & Gokwe & Gokwe GP & 1 & 19 & 20 \\
\hline & Mzingwane & Umzingwane & Mawabeni BC & 6 & 12 & 18 \\
\hline Mat South & Claremont & Umzingwane & Bulawayo & 2 & 4 & 6 \\
\hline Total & 11 & 8 & 11 & 49 & 176 & 225 \\
\hline
\end{tabular}

Source: 2018 household survey

Figure 1: Map of Zimbabwe Showing the Study Sites

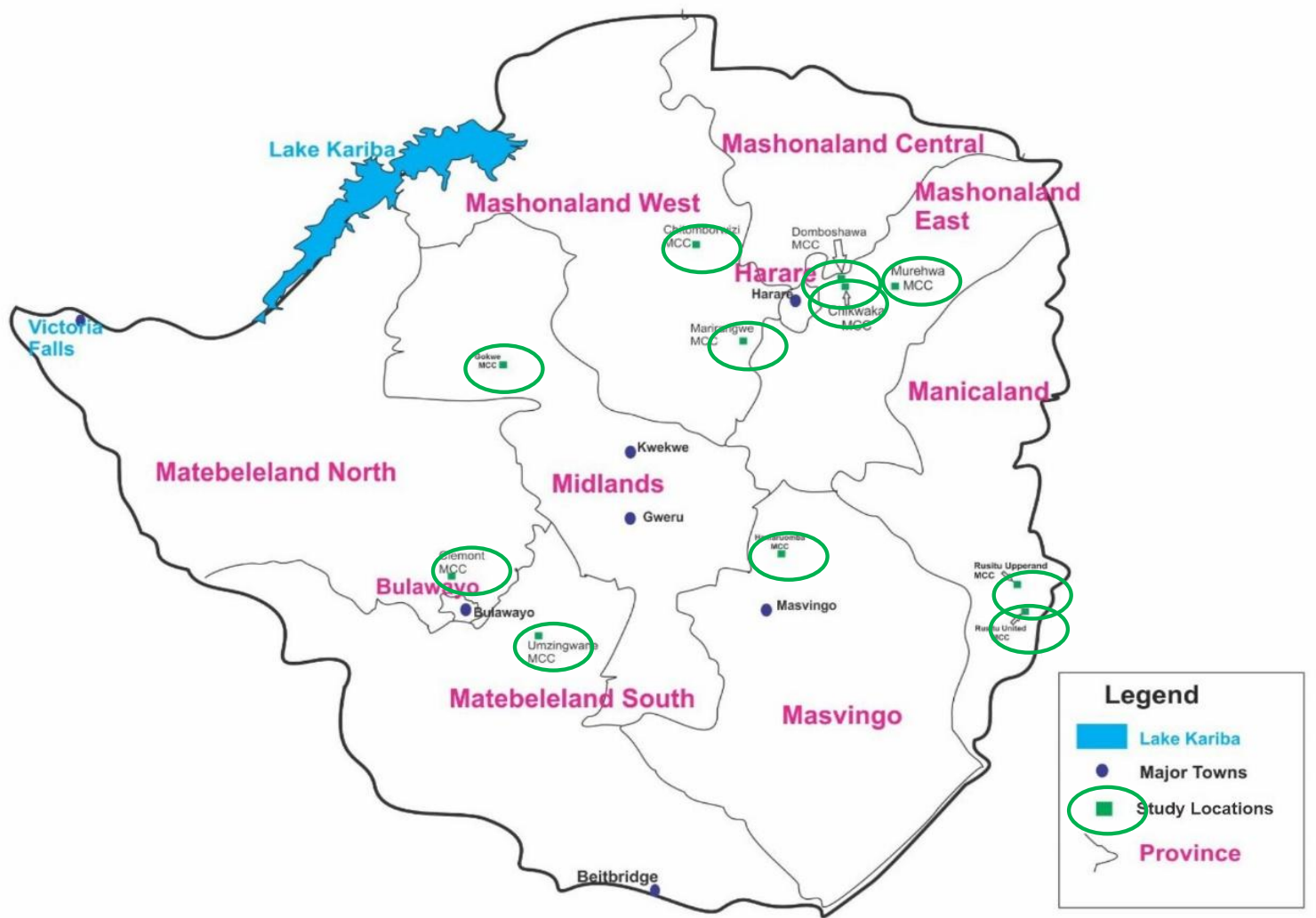

Source: Developed by the author. 
Data Collection: Primary quantitative data used for this study was gathered from the farmers using a structured questionnaire. Gray (2014) defined a questionnaire as a research tool which enables the researcher asks the targeted respondents to respond to similar questions in a predetermined order. According to Somekh \& Lewin (2005), questionnaires allows the collection of data in a standardised way. The questionnaire designed had clear objectives and was structured into sections to ensure that all relevant issues are addressed. The nature of the data that was collected from the farmers required the use of questionnaire consisting of both open-ended and close-ended questions. The questionnaire content validity was reviewed by a panel of experts associated with dairy farming and agricultural economics, and their suggestions were used to modify the items of the instrument. This was to ensure that the tool measured what it intended to measure; questions were worded, and statements in the questionnaire were not ambiguously stated. A pretest was conducted with 20 small scale dairy farmers, to establish the usability of the instrument. The data for the study was collected over a three months period which ran from May to July 2018.

Four highly experienced and qualified enumerators were recruited, trained, coached, mentored and guided to assist with the administration of questionnaires. All the four enumerators had good knowledge of the smallholder dairy farming systems and could speak the local languages (Shona and Ndebele). Before the actual interviews, the researcher trained the enumerators on how to interpret and ask each question. The enumerator training included two-day piloting of the tool on an accessible location. During piloting, the enumerators took detailed notes of the data collection process including detailed notes on how participants reacted to both the general format of the questionnaire and the specific details of the questions. The piloting also helped the research team to estimate the actual time required to complete each interview. Face-to-face interviews were conducted at each farmer home and targeting the household head. This method of interviewing minimises nonresponse while maximising the quality, reliability and usability of the data. Also, the face-to-face interview strategy in the presence of the interviewer makes allows the respondent to either clarify answers or ask for clarification for some of the potentially confusing portions of the questionnaire. This study involved collecting some potentially sensitive data such as income and costs.

Data Analysis: The data used for this study was analysed using the causal modelling technique. The actual analysis for this study was carried out using R software. The graphs were generated using the ggplot2 library that provides a lot of functions to generate bar graphs, histograms, scatter plots, and other charts. Further, the VGAM library was used to perform the OLS regression analysis. This library provides the LM function (which is part of the stats library) was used to perform OLS regression for hypothesis. The selection of appropriate statistical technique largely depended on the distribution of the study variables. The data analysis was divided into two parts, a descriptive analysis, and hypothesis testing using the OLS regression analysis. The OLS regression coefficients show the marginal effects and direction of change of the independent variables on the dependent variable.

Yield As a Proxy for Commercialization in Smallholder Dairy Farming: The low level of agricultural productivity, competitiveness and profitability among the smallholder farmers in developing countries has been widely researched (Shumba \& Whingwiri, 2006; World Bank, 2008; FAO et al., 2012; Dube \& Guveya, 2016; FAO., 2017). It is apparent that efforts to enhance the commercialisation of smallholder agriculture in developing countries will ultimately have minimum benefit if the challenges of low productivity among the smallholder producers is not adequately addressed (Arias et al., 2013). This study used milk yield for each household which is defined as the average milk produced per cow as the determinant of agricultural productivity among the small-scale milk producers in target locations. The minimum milk yield values range from zero upwards and theoretically, there is no upper limit, but values above 30 are rare. Though other factors may cause variations, under normal conditions, higher yields are associated with higher commercialisations and vice versa. Mathematically, it can be calculated as:

$$
\text { MilkYield }=\frac{\text { TotalMilkProduced }}{\text { TotalNumberofCows }}
$$

The Ordinary Least Squares (OLS) Regression Model: To estimate the econometric relationship between milk yields and the various determents of feeding and grazing management, the Ordinary least squares (OLS) regression model was used. The data used for this study consisted of observations that were drawn randomly from the population. The OLS regression model was estimated as: 


$$
Y_{i}=\beta_{0}+\beta_{1} X_{1}+\beta_{2} X_{2}+\beta_{3} X_{3}+\beta_{4} X_{4}+\beta_{5} X_{5}
$$

Where $\mathrm{Y}^{*}=$ Milk Yield; $\mathrm{Xi}$ is a vector of explanatory variables relating to the grazing and feed management factors that include feed type, feed season, pasture access, fodder area, and feeding frequency. The details of the variables are presented in Table 2 below.

Table 2: Variables Used in the OLS Model for Assessing the Effects of Feeding and Grazing on Milk Yield

\begin{tabular}{llr}
\hline $\begin{array}{l}\text { Study } \\
\text { Variable }\end{array}$ & Variable Description & Variable Type \\
\hline $\mathrm{Y}^{*}$ & $\begin{array}{l}\text { Milk Yield (litres/cow) } \\
\mathrm{X}_{1}\end{array}$ & $\begin{array}{l}\text { Type of feed used to feed the cows (1=Zero grazing, 2=Natural pastures, } \\
\text { 3=Purchased feed (concentrates) }\end{array}$ \\
$\mathrm{X}_{2}$ & $\begin{array}{l}\text { Supplementary feeding during the dry season. (1=Depends on the } \\
\text { situation, 2=Same for the dry and rainy season, 3=Supplement during the } \\
\text { dry season). }\end{array}$ \\
$\mathrm{X}_{3}$ & $\begin{array}{l}\text { Access to grazing pasture (1=Easily accessible, } \\
\text { 2=Difficult to access) }\end{array}$ \\
$\mathrm{X}_{4}$ & The area under fodder production (ha) \\
$\mathrm{X}_{5}$ & Feeding Frequency (1=None, 2=0nce, 3=Twice, 4=Thrice)
\end{tabular}

\section{Results and Discussion}

Descriptive Statistics: Table 3 below shows the summary information of cattle feeding by smallholder dairy farmers reached by this study. The table shows that close to half $(47.11 \%)$ of the respondents use open range grazing to feed their dairy cattle while $39.11 \%$ use the paddock grazing system and only $13.78 \%$ use zero grazing. All the farmers using both the open range and paddock grazing systems practically rely on natural pastures; therefore cumulatively $86.22 \%$ of the farmers use natural pastures. These results support the findings of a recent evaluation of small scale dairy farming in Zimbabwe conducted by the SNV Netherlands Development Services in 2012 which revealed that the use of natural communal grazing was very high across all projects (SNV, 2012). Similarly, a study by Ngongoni et al. (2007) on the factors affecting productivity in the small scale dairy sector of Zimbabwe shows that natural pastures account for $90 \%$ of the feed that is given to the dairy cows. The same study by Ngongoni et al. (2007) also shows that other feeds such as maize stover and fodder mainly Napier and Bana grass contributes the remaining $10 \%$ of the overall feed available in the smallholder dairy sector.

This makes it easier for them to sign commercial contracts with buyers and enhance their business. A study by Pandey \& Voskuil (2011) noted that milk productivity and the quantity of milk delivered to the market by commercial dairy farmers is usually constant throughout the year, but the quantity of milk produced by smallholder dairy farmers in developing countries significantly decreases by up to $35 \%$ during the dry season due to the shortage of appropriate feeds. The results in Table 3 shows that over half (57.33\%) of the surveyed farmers do not grow fodder at all. The practice by smallholder dairy farmers of using natural pastures as opposed to purchased feed or planted fodder is common not only in Zimbabwe but other developing countries as well. A report on enhancing productivity, profitability and investment attractiveness in Kenya's small scale dairy sector produced by the United States Agency for International Development (USAID) in (2018) reveals that majority of smallholder dairy farmers in Kenya predominantly rely on natural forage and where applicable small quantities of purchased concentrate on feeding their herds (USAID, 2018). 
Table 3: Summary Information on Cattle Feeding by Smallholder Dairy Farmers in Zimbabwe

\begin{tabular}{|c|c|c|c|}
\hline Study Variable & Details & Count & $\begin{array}{l}\text { Percentage } \\
(\mathrm{N}=225)\end{array}$ \\
\hline \multirow{3}{*}{ Grazing Method } & Open range grazing & 106 & 47.11 \\
\hline & Paddock grazing & 88 & 39.11 \\
\hline & Zero grazing & 31 & 13.78 \\
\hline \multirow{3}{*}{ Feed Type } & Natural pastures & 194 & 86.22 \\
\hline & Purchased feed (concentrates) & 31 & 13.78 \\
\hline & Depends on the situation & 6 & 2.67 \\
\hline \multirow[t]{2}{*}{ Feed Season } & Same for dry and rainy season & 134 & 59.56 \\
\hline & Supplement during the dry season and crop residue & 85 & 37.78 \\
\hline \multirow{2}{*}{ Pasture Access } & Easily accessible & 102 & 45.33 \\
\hline & Difficult to access & 123 & 54.67 \\
\hline \multirow{4}{*}{ Fodder Area } & None & 129 & 57.33 \\
\hline & 1-2 Acres & 65 & 28.89 \\
\hline & 3-5 Acres & 27 & 12.00 \\
\hline & 6 or more acres & 4 & 1.78 \\
\hline \multirow{4}{*}{$\begin{array}{l}\text { How many times } \\
\text { feed your cattle }\end{array}$} & None & 3 & 1.33 \\
\hline & Once & 46 & 20.44 \\
\hline & Twice & 124 & 55.11 \\
\hline & Thrice & 52 & 23.11 \\
\hline
\end{tabular}

Although very popular among the smallholder sector, the natural grazing systems provide an only limited capacity for intensification of dairy production. Research shows that under-nutrition through limited energy intake has negative effects on oestrus cycles, ovulation and fertilisation in dairy cows (Topps \& Oliver, 1993). Although some of the respondents (37.78\%) reported supplementing their feeding during the dry seasons, a significant proportion of the farmers (59.56\%) use the same feeding approach in both the rainy and the dry season. Given that natural pastures are usually scarce during the dry season that shows that the majority of dairy animals are nutritionally starved during the dry season. A study conducted by Marius et al. (2011) in Manicaland, Zimbabwe showed that the smallholder farming households that supplemented their feeding produced significantly more milk than those that did not supplement. Unlike the smallholder dairy farmers who struggle with feed during the dry seasons, the large scale commercial dairy farmers who consistently supplement their feeding and, in many cases, use zero grazing often get consistent milk volumes throughout the year.

A related study conducted in Zimbabwe by Marius et al. (2011) found that during the rainy season, the dairy animals even for the smallholder sector gained weight and milk production was high, while during the dry season the milk yield and body condition of the cows significantly declined. However given that majority of smallholder farmers do not manage their forages maximally to produce the highest yields of forage possible, a more realistic recommendation for smallholder farmers would be 6 to 8 milking cows per ha od forage (Moran, 2005). At 95\% confidence interval, the results show that household that reported using purchased feed have 4.328-unit higher milk yield compared to the households that reported using natural pastures for feeding the cows $(\mathrm{z}-\mathrm{val}=6.271$, $\mathrm{p}$-val $=0.000)$. The findings of this study agree with the results from a study by Kipkirui \& Otieno (2017) which showed that the poor quality and quantity of feeds are the main reason why smallholder dairy farmers in developing countries continue to produce low milk yields. In the absence of supplemented protein concentrate, the dairy cattle grazing natural pasture have high chances of losing body weight with cyclic ovarian activity ceasing.

When cows lose $20-30 \%$ of their mature weight due to undernutrition (Topps \& Oliver, 1993). To make dairy farming successful, it is crucial to have a reliable source of good quality feeds, fodder and grazing all year round (Pandey \& Voskuil, 2011). However, one of the major challnges affecting small scale dairy farming in Zimbabwe is accessing good, reliable and consistent pastures for their cows. Table 3 shows that over half of the respondents in this study (54.67\%) reported experiencing challenges accessing pastures. Given the limitations in natural pasture access which are apparent in many smallholder dairy farming areas, planting fodder is a feasible way of managing the dairy cattle feeds costs and access. According to Moran (2005) 
forages provide an alternative and cheaper source of the crucial feed nutrients when compared to concentrates. No matter the farmer circumstances, it is often cheaper for the farmer to grow the forages on the farm rather than purchase them from elsewhere. Farmers producing their forage on the farmer find it easier to control the quality than with purchased forages.

Figure 2: Pairwise Correlation between Milk Yield and Area Under Fodder
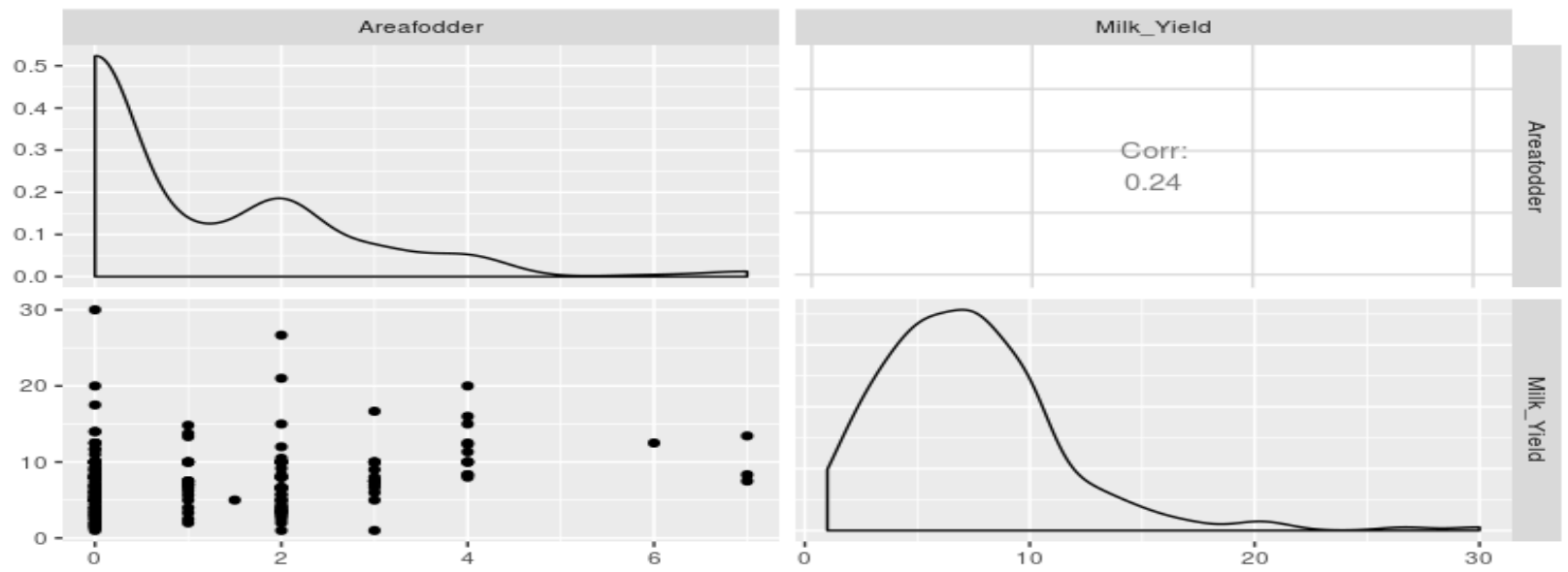

The histogram plot showing the distribution of area planted under fodder, and milk yield are summarised in a pair-wise correlation diagram in Figure 2. It can be observed that the distribution of respondents based on area under fodder is skewed towards left, indicating that most of the households have small fodder area to feed their cattle. On the contrary, the distribution of the milk yield is approximately normal with a heavy tail towards the right, indicate that some household has high milk yielding cows.

Effects of Grazing and Feed Management on Milk Yield: The Ordinary Least Squares (OLS) regression model was applied to examine the effects of grazing and feed management on the commercialisation of smallholder dairy farming using milk yield as the dependent variable. Table 4 below shows the results of the OLS model. In order to get a sense of the fitness of the OLS model two statistical tests were conducted, multiple squared correlations and the standard error of variance. The correlation between the predicted and observed values of Milk Yield is 0.7068. If we square this value, we get the multiple squared correlations; this indicates predicted values share $49.95 \%$ of their variance with milk yield. The standard error of variance indicates the distance between the data points and the regression line. The calculation indicates that the standard errors of the regression for all the variables fell below $5 \%$. This means that the standard variance between the observations and the regression line is below $5 \%$. Consequently, we can use the standard error to obtain a rough estimate of the approximately $95 \%$ prediction interval. Lower magnitudes of the standard error imply that the variances between the data points and the fitted values are smaller thereby making the model applicable.

Table 4: Ordinary Least Squares Regression Analysis Results

\begin{tabular}{|c|c|c|c|c|c|}
\hline $\begin{array}{l}\text { Variable } \\
\text { Name }\end{array}$ & Variable Description & Estimate/ Coef. & Std. Error & Z-value & $\mathbf{P}$-value \\
\hline (Intercept) & & 7.678 & 2.133 & 3.599 & 0 \\
\hline Fodder Area & Area planted by household under fodder (ha) & 0.342 & 0.143 & 2.392 & $0.018^{* *}$ \\
\hline \multirow{3}{*}{ Feed Type } & Use of purchased Feed Concentrates & 4.328 & 0.69 & 6.271 & $0.000^{* * *}$ \\
\hline & Use of Natural Feed Pastures & . & & & . \\
\hline & Same for day and rainy Season & -1.647 & 1.275 & -1.292 & 0.198 \\
\hline \multirow[t]{2}{*}{ Feed Season } & $\begin{array}{l}\text { Supplement During Dry Season and Crop } \\
\text { Residues }\end{array}$ & -0.536 & 1.282 & -0.418 & 0.676 \\
\hline & Depends on the Situation & . & . & . & . \\
\hline
\end{tabular}




\begin{tabular}{llllll}
\hline Pasture & Easily Accessible & 0.783 & 0.491 & 1.593 & 0.113 \\
Access & Difficult to Access during Dry Season & &. &. &. \\
& Once & -3.132 & 1.816 & -1.724 & $0.086^{*}$ \\
Feed & Thrice & 2.117 & 1.809 & 1.17 & 0.243 \\
Frequency & Twice & -0.617 & 1.767 & -0.349 & 0.727 \\
& None &. &. &. &. \\
\hline${ }^{*}$-val $<0.10, *$ p-val $<0.05, * * *$-va $<0.01, \mathrm{r}$-Square $=0.50$, (correlation coefficient $)=0.71, \mathrm{~F}(8,216)=26.95, \mathrm{p}$-val $<0.01$ & & &
\end{tabular}

As shown in Table 3 above, a significant number of farmers (57.33\%) do not grow fodder at all while only $12 \%$ grow more than 2 ha of fodder. These results suggest that in the absence of purchased feed concentrates which are often too costly for the resource-constrained smallholder producers, the majority of farmers rely on natural pastures. Interestingly, the OLS regression results show that there is a positive impact of area planted under fodder on the milk yield. It is observed that for every unit increase in the area planted under fodder, the household milk yield increases by 0.342 units (z-val $=2.392, p$-val $=0.018$ ). The low cultivation of fodder by small scale milk producers in Zimbabwe was also confirmed by a study by the SNV Netherlands Development Organization which reported that the average area which farmers in Zimbabwe allocated to fodder production was 0.9 ha $(\mathrm{SNV}, 2012)$. This study shows that almost $60 \%$ of the farmers are not growing fodder at all. Similarly, an assessment of small scale dairy farming in Zimbabwe conducted by the SNV Netherlands Development Services in 2012 revealed that the use of own silage.

Among the smallholder dairy farmers in Zimbabwe was still deficient most likely because of reliance on grazing. Despite this low cultivation of fodder, research shows that farmers cultivating their fodder save much money thereby growing their businesses substantially. According to Moran (2005), a farmer cultivating the maximum possible volumes of quality forages requires at least one hectare to adequately feed 8 to 10 milking cows. Similarly, a study by Aweke (2017) on major production challenges of dairy cows in Ethiopia identified poor grazing and management as one of the key production challenges. The regression results show that, at $90 \%$ confidence interval, we observe that households who reported feed frequency of one have 3.132 units lower milk yield compared to the households who reported no feed frequency $(\mathrm{z}-\mathrm{val}=-1.724$, $\mathrm{p}$ $\mathrm{val}=0.086$ ). Research shows that limited knowledge and experience on the use of locally available feedstuffs, lack of pasture seed limited access to land for pasture improvement, poor pasture management especially during the dry season collectively worsens the feed shortage especially during the dry seasons (Tebug, 2012).

\section{Conclusions and Policy Implications}

This study assessed how the different components of grazing and feeding management such as feed types, access to grazing pastures, grazing methods, feeding frequency, feed supplementation during the dry season, and area under fodder production are related to milk yield at farmer level. More than half of the respondents (57.33\%) had utterly no area under fodder production. Of those who planted fodder, only $12 \%$ planted more than 2 ha of fodder. Majority of the farmers, almost $90 \%$ rely on natural pastures to feed the cows. The results show that farmers putting more area under fodder production produce significantly more milk yield than farmers with less or no land under fodder production. Results also show that farmers relying on natural pastures to feed their cattle are getting significantly lower milk yield levels than farmers using dairy feed concentrates. Farmers with better access to pastures have significantly higher milk yield levels than farmers with poor access to grazing pastures. Likewise, dairy cattle that get supplementary feeding get significantly more yield levels than those that are not getting supplementary feeding during the dry season. Overall the results show that feeding is a crucial element of any dairy activity.

The conclusion is that the smallholder dairy farmers who have access to, enough, nutritious and consistent feed types are more likely to get better milk yields and to be market-oriented. Farmers should be advised to plan and secure feed ahead of time. Planning helps to ensure that the herd's feed requirements are met. This enhances good heard health and better productivity. Where applicable, farmers should aim to implement sustainable and economically viable ways of securing dairy feed such as growing their feed. In situations where producing their own feed is not possible for any reason such as limited access to land or lack of 
technical expertise, farmers can resort to purchasing feed from the suppliers. However, it is crucial to ensure the traceability and reliability of feedstuffs brought to the farm. It is recommended for the farmers to source animal feed from those suppliers having an approved quality assurance system in place and at all costs prevent the use of feeds that are not suitable for dairy animals. Moreover, farmers should also keep accurate records of all feed and feed ingredients used on the farm.

\section{References}

Afzal, M. (2010). Re-designing Smallholder Dairy Production in Pakistan. Pakistan Veterinary Journal, 30(3), 187-190.

Arias, P., Hallam, D., Krivinos, E. \& Morrison, J. (2013). Smallholder integration in changing food markets Smallholder integration in changing food markets. Rome.

Aweke, S. (2017). Major Production Problems of Dairy Cows of Different Farm Scales Located in the Capital City Addis Ababa, Ethiopia. Journal of Veterinary Science \& Technology, 08(06), 6-11.

Chamboko, T. \& Mwakiwa, E. (2016). A review of smallholder dairy development in Zimbabwe from 1983 to 2013: The effect of policies. Livestock Research for Rural Development, 28(6), 18.

Dube, L. \& Guveya, E. (2016). Determinants of agriculture commercialisation among smallholder farmers in Manicaland and Masvingo Provinces of Zimbabwe. Agricultural Science Research Journal, 6(8), 182190.

Food and Agriculture Organization of the United Nations (FAO). (2010). Status of and Prospects for Smallholder Milk Production - A Global Perspective. T. Hemme \& J. Otte, eds. Rome, Italy: Food and Agriculture Organisation of the United Nations.

Food and Agriculture Organization of the United Nations (FAO). (2017). The future of food and agriculture Trends and challenges. Rome: Food and Agriculture Organization of the United Nations.

Gachuiri, C. L., Likuyu, M. N. \& Ahuya, C. (2012). Dairy farmers' Training Manual: Kenya USAID Dairy Sector Competitive Programme,. Nairobi.

Gerosa, S. \& Skoet, J. (2012). Milk availability: Trends in production and demand and medium-term outlook. Rome,

Gran, H. M., Mutukumira, A. N., Wetlesen, A. \& Narvhus, J. A. (2002). Smallholder dairy processing in Zimbabwe: The production of fermented milk products with particular emphasis on sanitation and microbiological quality. Food Control, 13(3), 161-168.

Gray, D. E. (2014). Doing Research in the Real World. Sage Publication, London

Hanyani-Mlambo, B. (2000). Smallholder Dairy Production and Marketing in Zimbabwe : A socio-economic study of the Gokwe, Rusitu and Marirangwe dairy development projects. Harare.

Israel, G. D. (2003). Determining Sample Size. University of Florida IFAS Extension, 1-5.

Kandjou, M. J. (2011). Technical challenges and agribusiness prospects for developing pro-poor small scale dairy processing schemes in Omaheke region of Namibia. University of Zimbabwe.

Kipkirui, M. \& Otieno, M. M. M. (2017). Factors Influencing Milk Production Project Among Small Scale Dairy Farmers in Bomet East Sub County, kenya. International Journal of Latest Research in Engeneering Technology (IJLRET), 03(09), 1-23.

Land O'Lakes. (2010). The next stage in dairy development for Ethiopia: Dairy Value Chains, End Markets and Food Security. Addis Ababa, Ethiopia. https://www.usaid.gov/sites/default/files/documents/1860.

Marius, L. N., Imbayarwo-Chikosi, V. E., Hanyani-Mlambo, B. T. \& Mutisi, C. (2011). Breed preferences, production performance and management of dairy cattle among selected smallholder farmers of Zimbabwe. AGRICOLA, 2-5.

Matekenya, T. (2016). Large Scale Dairy Value Chain in Zimbabwe: A Paper Presented to Division of Livestock Research, DR\&SS, (November), 24.

Meja, H. A., Musyoka, T. \& Kibaki, P. (2017). Socio-cultural features on commercialization of smallholder dairy value chain growth in Kenya. Global Journal of Dairy Farming and Milk Production, 5(3), 287-298.

Moran, J. (2005). Tropical Dairy Farming: Feeding Management for Small Holder Dairy Farmers in the Humid Tropics. CSIRO, Melbourne: Landlinks Press.

Moran, J. B. (2009). Key Performance Indicators to diagnose poor farm performance and profitability of smallholder dairy farmers in Asia. Asian-Australasian Journal of Animal Sciences, 22(12), 1709-1717.

Mpofu, N. (2007). Strategies for dairy cattle breeding to ensure sustainable milk production: A paper presented at the national dairy symposium: Resuscitating the dairy industry in Zimbabwe held on 
July 5th - 6th 2007. Harare.

Muehlhoff, E., Bennett, A. \& McMahon, D. (2013). Milk and dairy products in human nutrition.

Mugweni, L. \& Muponda, G. (2015). Small-Scale Dairy Farming in Zimbabwe. International Journal of Economics, Commerce and Management, III(8), 448-466.

Mupunga, E. G. \& Dube, D. M. J. (1993). Smallholder dairy development programme in resettled and communal areas in Zimbabwe. Future of livestock industries in east and southern Africa: Proceedings of the Workshop held at Kadoma Ranch Hotel, Zimbabwe, 20-23 July 1992, 165-172.

Netherlands-African Business Council (NABC). (2014). Factsheet - Dairy sector Ethiopia, 5.

Ngongoni, N. T., Mapiye, C., Mwale, M. \& Mupeta, B. (2007). Effect of supplementing a high-protein ram press sunflower cake concentrate on smallholder milk production in Zimbabwe. Tropical Animal Health and Production, 39(4), 297-307.

Ngongoni, N. T., Mapiye, C., Mwale, M. \& Mupeta, B. (2006). Factors affecting milk production in the smallholder dairy sector of Zimbabwe. Livestock Research for Rural Development, 18(6), 1807218072.

Omiti, J. M., Otieno, D. J., Nyanamba, T. O. \& Mccullough, E. (2009). Factors influencing the intensity of market participation by smallholder farmers : A case study of rural and peri-urban areas of Kenya. World, 3(1), 57-82.

Pandey, G. S. \& Voskuil, G. C. J. (2011). Manual on Improved Feeding of Dairy Cattle by Smallholder Farmers: For Extension Workers and Dairy Farmers, (May), 1-52.

Personal, M., Archive, R., Kundurjiev, T. \& Salchev, P. (2011). Mp r a , (28953).

Rodriguez, G. (1987). The impacts of the milk pricing policy in Zimbabwe The Dairy Marketing Board : Its role in the price policy, $1-3$.

Shumba, E. \& Whingwiri, E. (2006). Commercialization of smallholder agriculture. In R. Mandivamba, E. Carl, T. Patrick, M. Munyuki-Hungwe, \& P. Matondi, eds. Zimbabwe's Agricultural Revolution Revisited. Harare: University of Zimbabwe Publications, 631-718.

SNV. (2012). Evaluation of Smallholder Dairy Programmes in Zimbabwe. Harare.

Somekh, B. \& Lewin, C. (2005). Methods in the Social Science. Sage Publications, London

Tebug, S. F. (2012). Smallholder dairy farming in Northern Malawi: husbandry practices, constraints and prevalence of major production and zoonotic diseases. University of Kiel.

Topps, J. H. \& Oliver, J. (1993). Animal foods of Central Africa. Zimbabwe Agricultural Journal, Technical Handbook number 2. Revised Edition.

United States Agency for International Development (USAID). 2018. Policy brief: enhancing investment attractiveness in Kenya's dairy sector. Nairobi, Kenya. 